\title{
ethic@ \\ A VIRTUDE DA SOLIDARIEDADE NA HERMENÊUTICA ENQUANTO UM JOGO DE FUSÃO DE HORIZONTES
}

\author{
THE VIRTUE OF SOLIDARITY IN HERMENEUTICS \\ AS A PLAY OF FUSION OF HORIZONS
}

\author{
LUIZ ROHDEN ${ }^{1}$ \\ (UNISINOS/Brasil)
}

\begin{abstract}
RESUMO
O objetivo deste paper é explicitar e fundamentar a virtude da solidariedade subjacente à teoria e à prática da Hermenêutica Filosófica de Hans-Georg Gadamer, a qual é imprescindível para alcançarmos nossa felicidade e criarmos um ethos de responsabilidade mútua. Embora Gadamer não tenha dito ou sustentado essa hipótese, mostrarei sua plausibilidade lógica bem como pertinência teórica e prática. Para tanto, mostrarei as relações íntimas entre Hermenêutica e Solidariedade enquanto jogos de fusão de horizontes regidos pelo pressuposto de que somos seres linguísticos que visamos, desde os primórdios da humanidade, de uma ou de outra forma, instituir um ethos de parceria, de harmonia e de cooperação mútua. Justificarei isso explicitando, inicialmente, significados e sentidos do termo Solidariedade em Gadamer, denominando-o um jogo com regras e finalidades próprias de uma virtude ética enquanto contenção de si e instituição do bem. Aprofundarei, a seguir, elos entre Hermenêutica e Solidariedade a partir dos temas da linguagem e da tradição enquanto exercícios de fusão de horizontes pautados pela instituição do acordo consigo mesmo e com os outros. Ao final, apontarei algumas implicações para nossa realização pessoal e social bem como para proteção da natureza.
\end{abstract}

Palavras-chave: Solidariedade; Hermenêutica; Jogo; Fusão de Horizontes; Gadamer.

\begin{abstract}
The purpose of this paper is to render explicit and substantiate the virtue of solidarity that underlies Hans-Georg Gadamer's theory and practice of Philosophical Hermeneutics and is essential to achieve our happiness and create an ethos of mutual responsibility. Although Gadamer has not enunciated or supported this hypothesis, I will show its logical plausibility as well as its theoretical and practical pertinence. To this end, I will show the intimate relations between Hermeneutics and Solidarity as games of fusion of horizons governed by the assumption that we are linguistic beings who aim, from the dawn of humanity, to establish, in one way or another, an ethos of partnership, harmony and mutual cooperation. I will justify this by first explaining senses and meanings of the term Solidarity in Gadamer by calling it a game with rules and purposes peculiar to an ethical virtue of self-restraint and institution of the good. Subsequently, I will elaborate on the links between Hermeneutics and Solidarity based on the topics of language e tradition as exercises of fusion of horizons guided by the institution of an agreement with oneself and with others. Concluding, I will point out some implications for our personal and social fulfillment as well as for the protection of nature.
\end{abstract}

Keywords: Solidarity; Hermeneutics; Play Fusion of horizons; Gadamer.

Se não apreendermos a virtude da hermenêutica, isto é, se não reconhecermos que se trata, em primeiro lugar, de compreender o outro, a fim de ver se, quem sabe, não será possivel, afinal, algo assim como solidariedade da humanidade enquanto um todo... (GADAMER, 2000, p. 25).

Na solidariedade que se declara, seja livremente ou à força, há sempre, em qualquer caso, uma renúncia aos interesses e preferências mais próprios. A solidariedade nos faz renunciar a certas coisas em uma certa direção, em um certo momento, a serviço de um certo objetivo (GADAMER, 2002, p. 86). 


\section{Introdução}

Proponho investigar as relações entre hermenêutica e solidariedade com o escopo de fundamentar a proposta da hermenêutica enquanto ética. Na filosofia em geral, "o que deu a esse tema seu poder de propagação não foi a questão social, mas sim a questão moral. A doutrina da solidariedade é, essencialmente, uma doutrina moral. Seus teóricos, quer sejam naturalistas, sociólogos, economistas ou juristas, são principalmente militantes da moral" (CANTOSPERBER apud LOPES, 2015, p. 79). Na tradição hermenêutica, ela não foi objeto de análise e de reflexão e, por isso, aqui, pretendo mostrar sua pertinência teórica e prática enquanto uma virtude própria da hermenêutica filosófica.

Considero crucial compreender a hermenêutica enquanto exercício ético à luz da solidariedade como um jogo de fusão de horizontes por dois argumentos: a) explorar o tema da solidariedade significa, em verdade, explicitar nosso modo natural de ser linguístico-político na trilha da tese segundo a qual somos zoon logikon e zoon politikon. Enquanto criadores de linguagem, procuramos, com ela e por meio dela, instaurar, em última instância, um ethos mais harmônico, solidário; b) diante da marcha acelerada da autodestruição planetária e da onda crescente de radicalismos de toda ordem, que pressupõem e implicam a destruição do outro, se torna oportuna a reflexão sobre o jogo da solidariedade ínsito à teoria e à prática hermenêuticas. Proponho justificar a urgência de aprimorarmos a arte de aprender a lidar com o outro, com a natureza enquanto nossos parceiros e não como objetos de uso e desuso ou de exploração predatória. As chances da sobrevivência humana e de uma vivência mais harmônica e responsável dependem, em grande parte, do esforço e do exercício de saber lidar com o outro, de jogarmos o jogo da fusão de horizontes.

1. Sobre a concepção de solidariedade em Gadamer

Embora Gadamer a tenha tematizado em palestras e ensaios após a publicação de Verdade e o Método, "ela já está presente indiretamente na grande obra. Solidariedade, o sentido de uma vida compartilhada, não é mencionada em Verdade e no Método, mas nunca esteve longe das principais preocupações do trabalho" (LAWN; KEANE, 2011, p. 132). Mesmo não havendo "uma única referência à noção de solidariedade em Verdade e Método" o fato é que "em muitos trabalhos subsequentes e entrevistas, o conceito recebe cada vez mais atenção" (LAWN, 2007, p. 140). Além disso, ao tematizá-lo, ele o vincula a "preocupações culturais e políticas" (LAWN; KEANE, 2011, p. 134). Em todo o caso, encontramos menções e dicas em seus textos $^{2}$, ainda que incipientes, da sua concepção de solidariedade, que servirão de base para sua 
fundamentação. Aliás, já no próprio termo Verstehen, encontramos indícios da solidariedade, na medida em que compreender implica se colocar, se imaginar, se pôr no lugar do outro para então instituir uma linguagem ou dizer ou poder agir de um ou de outro modo.

Da pesquisa brasileira, destaco a dissertação de Maria Aparecida dos Santos Lopes, $A$ solidariedade como praxis hermenêtica em Gadamer, apresentada, em 2015, no PPGFilosofia da UFPI e artigo do prof. Gustavo Silvano Batista, "Hermenêutica, Práxis e Solidariedade". Tratam-se de excelentes textos sobre a solidariedade em Gadamer, enquanto filosofia prática, nos moldes da phrônesis de Aristóteles.

\subsection{Sobre o termo solidariedade em Gadamer: fenomenologia e prospecção}

Ao investigar essa temática em Gadamer, Lawn retomou a seguinte definição de solidariedade: "uma unidade ou relação e responsabilidade ou ação, especialmente entre individuos com um interesse comum" (LAWN, 2007, p. 140). Além disso, ela "é uma base discutível para um programa de valores éticos e políticos" (LAWN, 2007, p. 140). Estou de acordo com essa tese, a qual me deu ensejo de explorá-lo do ponto de vista ético.

De acordo com Gadamer, "por detrás desta expressão está o termo latino solidum, que desempenha também seu papel na expressão soldo. Significa que o que importa é que como remuneração não se dê a alguém, por exemplo, moeda falsa. Tem que ser dinheiro válido, que tem valor" (GADAMER, 2002, p. 86).

Em termos fenomenológicos e de prospecção, em primeiro lugar, Gadamer sustenta que a humanidade chegou onde chegou, ou seja, sobreviveu, graças à sua prática, por assim dizer, natural, de solidariedade, de camaradagem, de parceria, calcadas sobre suas escolhas:

é um fato que a evolução biológica a que devemos nossa existência não nos tem dotado de instintos seguros para toda classe de decisões (...) nos vemos obrigados a eleger entre opções diversas, e estamos sempre expostos a fazer a eleição equivocada (GADAMER, 2002, p. 87).

As nossas escolhas, decisões e ações não são, essencialmente, determinadas por fatores biológicos, sociais, mas se estribam também em nossa capacidade de discernir e decidir. Assim, por um lado, chegamos onde chegamos porque optamos pelo caminho da solidariedade e, por outro lado, aprendemos que "a convivência entre as pessoas seria impossível se não houvesse entre elas algo assim como uma certa camaradagem" (GADAMER, 2002, p. 87), própria do exercício da solidariedade. 
Em segundo lugar, mesmo diante da crescente ênfase dada às especializações, em diferentes âmbitos da vida humana, Gadamer detecta e defende a existência de uma rede subterrânea de solidariedade com a qual temos muito que aprender:

\begin{abstract}
Estou convencido que, mesmo em uma sociedade altamente burocratizada, rigorosamente organizada e rigorosamente especializada, é possível fortalecer solidariedades existentes. Nossa vida pública me parece defeituosa ao dar muita ênfase ao diferente e ao disputado, ao que é contestado ou duvidoso. O que realmente temos em comum e o que nos une permanece, por assim dizer, sem voz. Provavelmente estamos colhendo os frutos de um longo treino na percepção de diferenças na sensibilidade demandada por ela. Nossa educação histórica aponta para essa direção, nossos hábitos políticos permitem que as confrontações e a atitude belicosa tornem-se lugares comuns. Na minha visão só poderíamos ganhar ao contemplar as profundas solidariedades que subjazem a todas as normas da vida humana (LAWN; KEANE, 2001, p. 135).
\end{abstract}

Em terceiro lugar, para mostrar a consistência conceitual e atualidade da solidariedade, Gadamer a vincula ao conceito de amizade, à philia grega. Se, por um lado, junto aos gregos, "a amizade funda-se (...) no sentimento da solidariedade", por outro lado, "a convivência humana nunca se institui noutra base a não ser a da solidariedade vigente" (GADAMER, 2001, p. 106). Visto assim, "a perda de toda a solidariedade significa o sofrimento do isolamento", pois "a solidariedade pressupõe sempre o que os gregos designavam como amizade consigo próprio" (GADAMER, 2001, p. 106). Em outras palavras, a tese de Gadamer é de que, "quem não é amigo de si, mas consigo está desunido, não é capaz de se entregar aos outros nem de atuar solidariamente" (GADAMER, 2001, p. 108).

Em quarto lugar, os acordos ou leis não escritas, vigentes na linguagem, foram tecidos, ao longo do tempo, por motivações éticas - ou seja, com vistas à instituição e à garantia das felicidades individuais -, mas também por razões sociais e políticas. Mais que simplesmente um acordo de pano de fundo vigente na tradição, ela, para Gadamer, constitui e é

parte de uma agenda de aspirações políticas e éticas para o futuro. Apesar de a tradição depender da solidariedade, há, muitas vezes, a esperança de que as solidariedades possam ser estendidas e expandidas. É neste sentido mais utópico da esperança que a solidariedade de Gadamer se move em seus trabalhos mais recentes (LAWN, 2007, p. 140).

Em quinto lugar, podemos extrair uma série de vantagens ao elucidar e fomentar os acordos ou leis não escritas, vigentes na linguagem, pelo fato de estarem "mais sólidas e profundamente emaranhadas na malha (tradicional) da vida social" e por oferecerem "uma esperança mais realista para a expansão das formas de mutualidade e do comum, nas quais a solidariedade em si depende" (LAWN, 2007, p. 145). Gadamer corrobora isso citando "o 
movimento de protesto contra o poder atômico, e a luta pela proteção legal aos animais, à natureza e às crianças, como exemplos de solidariedades genuínas que oferecem esperança para o futuro" (LAWN, 2007, p. 146). Contudo, mais candente ainda nesses dias, na roda das discussões sociais e políticas, nacionais e internacionais, encontra-se o tema da ecologia. Há uma solidariedade implícita e explícita em torno da premente necessidade de protegermos o meio ambiente por inúmeras razões que não vêm ao caso agora explicitar. O fato é que "o problema da ecologia impõe-se aqui por si mesmo", ou seja, "a natureza é uma realidade, que não se pode ser tratada segundo as leis do medir e do calcular", como se fosse um objeto manipulável e descartável, mas precisa ser levada a sério no sentido de que é uma realidade com a qual e na qual "se tem de aprender a viver, de tal modo que se respire mais livremente" (GADAMER, 2000, p. 22-23). Embutida nessa solidariedade ecológica planetária, encontra-se a crescente solidariedade para com os animais em geral estampada, por exemplo, na discussão sobre seus direitos e sua racionalidade. Gadamer também mencionou isso como exemplo de acordo vigente na sociedade contemporânea: “o mesmo vale para o que a própria pessoa sente ao comportar-se adequadamente, quando observa animais em suas formas de vida - cuidando de respeitá-los, da mesma maneira como o faria ao observar outras pessoas nos seus diversos modos de vida e de convicções" (GADAMER, 2000, p. 22-23). Dito isso, podemos dizer que a solidariedade corporifica-se como um jogo - com suas regras, exigências, finalidade - que precisa ser jogado para nos realizarmos plenamente e ainda podermos salvar nosso planeta.

\subsection{Condições e finalidades do jogo da solidariedade}

De acordo com Gadamer, "dizemos que nos declaramos solidários a respeito de algo", mas “o que queremos aqui dizer com o termo solidário?" cuja resposta dá algumas dicas significativas sobre sua compreensão de solidariedade enquanto um jogo, a saber,

na solidariedade que se declara (...) há sempre, em qualquer caso, uma renúncia aos interesses e preferências mais próprios. A solidariedade nos faz renunciar a certas coisas em uma certa direção, em um certo momento, a serviço de um certo objetivo" (GADAMER, 2002, p. 86) (grifos meus).

Com o escopo de desvelar seu modo de proceder, mostrarei que a solidariedade constitui um jogo que, como todo jogo, possui suas condições e objetivos. Quanto às regras e às condições, o jogo da solidariedade, jogado pela humanidade desde os seus primórdios, implica a renúncia a certos "interesses e preferências mais próprios" em "rumo a uma certa direção". O jogo, para ser bem jogado, exige e pressupõe a "contenção da subjetividade" (GADAMER, 
2002, 552). Essa contenção se refere à renúncia aos interesses particulares - ou ao modo exclusivo de ser do ser enquanto, por exemplo, um cogito ergo sum - e à defesa do interesse do bem público. A outra face do jogar que pressupõe a renúncia - isto é, de não dominar, instrumentalizar, objetificar - implica uma atuação que é de parceria, de envolvimento, de intercâmbio, próprio do jogo da solidariedade.

O jogo ou exercício de aprender a acolher e a trabalhar com a possibilidade do outro ter direito de jogar e possa ter razão em suas jogadas, pressupõe e implica autolimitação e autocontrole por parte do jogador. O jogador que pretende determinar o movimento total do jogo deixa de atuar solidariamente e, por isso, não joga efetivamente. O dogmático e o totalitário não sabem e/ou não querem nem pretendem jogar verdadeiramente porque não lhes interessa levar a sério o direito do outro de jogar. Contudo, mesmo nas práticas diárias mais elementares para implementar o ethos do bom convívio, é imprescindível aprender a autolimitar-se: “mesmo na conversação de negócio confirma a nota geral do diálogo: para ser capaz de dialogar há que saber ouvir. $\mathrm{O}$ encontro com o outro se produz sobre a base de saber autolimitar-se, inclusive quando se trata de dólares ou de interesses de poder" (GADAMER, 1992, p. 208). A solidariedade, enquanto um jogo dialógico, pressupõe, pois, o constante exercício de autolimitação para alcançar a meta do jogo.

Não se trata de autopunição do jogador, mas da sua auto-realização, pois, enquanto animais linguísticos e políticos, é no jogo solidário com outro que se encontra o exercício de nossa felicidade e realização plenas. Essa regra do jogo solidário não esvazia o eu, mas o estimula ao exercício do ouvir constante, do reconhecimento e acolhimento do direito e do argumento do outro. Essa regra, própria de todo jogo, faz uma remissão aos temas éticos da empatia, da tolerância, do respeito, implicados no jogo da solidariedade. A plenitude desse jogo da solidariedade efetiva-se no jogo dialógico que faculta a instauração da tradição, da história, segundo o pressuposto de que a "vida social é sublinhada por variedades de acordo linguístico, mas elas estão em constante jogo livre de interpretação" (LAWN; KEANE, 2011, p. 134).

Considerando a solidariedade como um jogo, vimos suas exigências e nos resta agora explicitar sua finalidade. Gadamer se considera platônico - o que indica a gênese ética da sua hermenêutica. Em suas obras, Platos dialektische Ethik - beim Wort genommen (Cf. GADAMER, 1991) e Die Idee des Guten zwischen Plato und Aristoteles (Cf. GADAMER, 1991), ele sustenta "o bem como origem e finalidade da dialética" (SAUTEREAU, 2013, p. 263). Em Platão, a dialética tende, em última instância, em direção ao bem "como se pode ler na República onde "no que se pode conhecer, em último termo, é a forma do Bem"” enquanto uma "estrutura absoluta que rege todas as coisas (...) e que deve guiar uma vida sensata" 
funcionando como "princípio e fim" metaforicizado pelo significado do sol para o mundo físico (SAUTEREAU, 2013, p. 263).

Contudo, Gadamer "não concebe o bem como algo transcendente, como uma ousia, ou essência nos moldes da concepção de Platão desenvolvido no livro VI da República", mas o trata como desenvolvido no Filebo, a saber, à luz da

questão socrática do bem humano. 'Ele se põe, escreve Gadamer, como a questão sobre a arété, com todas suas ramificações, como a questão relativa aos aretai (...) em um domínio estritamente delimitado, sendo este o do bem na vida humana'. A questão de Sócrates, no Filebo, é assim de determinar qual é para o homem o bem por excelência (SAUTEREAU, 2013, p. 265).

O jogo da solidariedade visa compreender e efetivar esse bem. À luz da filosofia prática de Aristóteles e da noção de bem desenvolvida no Filebo, "a perspectiva prática não é perdida de vista. A razão deve, pois, guiar a efetivação do bem", ou seja,

assim como Aristóteles sabe que sua reflexão teórica, que ele chama de ética, deve servir à vida realmente vivida, fica claro para Platão e o leitor do Filebo que o resultado do diálogo, o ideal de uma vida harmoniosa, é, como tal, um logos que se refere a um ergon: escolha o justo no momento da escolha (SAUTEREAU, 2013, p. 275).

Gadamer se apropria dessa perspectiva de dialética platônica de modo que, para ele, é o diálogo hermenêutico que fomenta e também "cria uma solidariedade entre aqueles que buscam o bem comum" que, por sua vez, enriquece "a compreensão de si, dos outros e do mundo e nos ajuda a deliberar quanto às questões essenciais da existência humana e a guiar nossa ação" (SAUTEREAU, 2013, p. 275).

Com vistas a uma compreensão mais completa do conceito de solidariedade enquanto um jogo ético, explorarei relações com o tema da linguagem e da tradição explicáveis pela noção de fusão de horizontes.

2. Relação entre solidariedade e linguagem, tradição enquanto fusão de horizontes

Conforme Gadamer, na opinião de Lawn, "uma das principais características da tradição são o comum e a estrutura implícita dos acordos que oferecem uma plataforma essencial para o entendimento" sendo que "a linguagem e a história são sinônimos da tradição. Da mesma forma, a linguagem e a história pressupõe formas de solidariedade" (LAWN, 2007, p. 140). 


\subsection{Solidariedade e linguagem}

Lawn e Keane apontam a relação íntima entre linguagem e solidariedade em Gadamer nos seguintes termos: "a linguagem é possível graças, em larga medida, a uma vida compartilhada; podemos até dizer que uma solidariedade básica é uma pré-condição da linguagem" (LAWN; KEANE, 2011, p. 132). Mais que mera representação formal ou designativa do mundo - na direção proposta pelo Crátilo de Platão -, a linguagem o constitui graças a uma "rede de acordos comuns e consensuais" (LAWN; KEANE, 2011, p. 132). Visto assim, podemos dizer que linguagem e solidariedade são conceitos conversíveis na medida em que um pressupõe e implica o outro.

Há uma unidade originária entre a postura solidária e a criação de linguagem que ecoa a definição de ser humano enquanto zoon logikon e zoon politikon proposto pelo estagirita. $\mathrm{O}$ cultivo de redes relacionais que se corporifica, em termos teóricos e práticos, na tradição, é também princípio e fim ou pressuposto e escopo da elaboração de linguagem. E por outro lado, o significado e o sentido, ou "a compreensão e a linguagem são atualizadas porque certas solidariedades estão no centro de todos os nossos empreendimentos hermenêuticos e interpretativos" (LAWN; KEANE, 2011, p. 133). E, mais radicalmente ainda, a quebra ou as rupturas ou as faltas de sentido e significados, só ocorrem quando, "em alguma medida de acordo já existe", de acordo com Gadamer, que diz que "falhas de comunicação não ocorreriam se não tivéssemos percorrido um longo caminho juntos (...) toda solidariedade humana, toda estabilidade social pressupõe isso"” (LAWN; KEANE, 2011, p. 133). Enfim, o cultivo de um ethos harmônico e permeado pela responsabilidade passa, dialeticamente, pela criação e compreensão da linguagem.

\subsection{Solidariedade e tradição}

Há uma série de elos entre hermenêutica e a tradição relacionada à solidariedade na obra de Gadamer. Lawn lembra que, a partir da década de 60, o conceito de tradição vai rareando em sua obra, o que o levou a propor a tese radical sobre o papel da solidariedade em Gadamer: "a solidariedade se transforma numa substituição para a tradição inicial, ou numa maneira de amplificar e expandir sobre ela" (LAWN, 2007, p. 140) (grifos meus). A plausibilidade lógica dessa sugestão e mudança estriba-se no fato de que a tradição, 
de uma tradição constantemente em mudança, e ainda assim a tradição em si é baseada em acordos profundos, e seria possível igualar tais acordos com uma forma de solidariedade (LAWN, 2007, p. 140).

Estou de acordo, em parte, com essa proposição, na medida em que há uma substituição - ou, melhor, talvez, apenas uma conversão - de um conceito por outro, porque ambos funcionam como condutos por meio dos quais "elementos centrais da vida social" realizam a interconexão entre passado, presente e futuro, graças aos acordos de fundo, leis não escritas que comportam. Por outro lado, tenho a impressão de que o conceito de tradição é mais amplo e engloba mais aspectos; além disso, os acordos de solidariedades podem ser restritos a grupos específicos no bojo de uma tradição que os engloba. Mais que mera substituição do conceito de tradição, sugiro que consideremos a solidariedade como seu fio condutor com função ética ao instituir e fomentar acordos com vistas à efetivação do bem comum.

A comparação da visão de solidariedade entre Rorty e Gadamer, nos oferece elementos para sua compreensão conforme nos propõe Lawn. De acordo com Gadamer, "as solidariedades são reclamadas e reveladas dentro de uma malha de linguagem e tradição" e Rorty "fala das solidariedades em termos de criação e invenção" (LAWN, 2007, p. 144). Em contraposição a ele, Gadamer reivindica que "não precisamos inventar (...) solidariedades", mas que "precisamos simplesmente nos conscientizar delas" (LAWN, 2007, p. 144). Movido pela esperança de um mundo mais justo, melhor, destaca os aspectos éticos contidos no caldo cultural (LAWN, 2007, p. 145-146) que nos mantém vivos, em casa, e que precisamos fomentar. Não vejo dificuldade em sustentar uma terceira possibilidade, a saber, a de conciliar, dialeticamente, as posições, pois, além de estimular a efetivação da solidariedade por meio de uma leitura fenomenológica, estou de acordo que a literatura tem também uma função (Cf. ROHDEN, 2019) decisiva na sua compreensão, valorização e atualização.

Desenvolvemos a noção de solidariedade enquanto um jogo, com suas regras e cuja finalidade é atualizar acordos de convivência harmônicos e responsáveis. Aprofundaremos os elos entre tradição, linguagem e solidariedade do ponto de vista do modo de proceder ou do modelo estrutural (ROHDEN, 2002) da fusão de horizontes. Na opinião de Lawn e Keane,

A linguagem sempre fala de um local ou horizonte, mas esse horizonte é definido e limitado por sua relação com outros horizontes a partir dos quais novos significados são produzidos. A idéia da fusão de horizontes traz à tona certas características da linguagem e do social. Como os horizontes estão necessariamente em relação aos outros, eles estão constantemente em processo de renegociação. A idéia de fusão sugere a possibilidade de conciliação e compromisso, sugerindo uma falibilidade profunda em nossos encontros com o outro. Ao mesmo tempo, sugere a possibilidade de ampliar e expandir horizontes. É nesse ponto que podemos considerar a fusão como 
uma expansão não apenas de experiência e compreensão, mas como uma extensão de solidariedades (LAWN; KEANE, 2011, p. 132-133).

Estou de acordo com os autores mencionados acima, na medida em que a fusão de horizontes permeia a instituição da linguagem, da tradição, da história, as quais, por sua vez, pressupõem e implicam a efetivação de práticas solidárias. O reconhecimento e a incorporação do horizonte do outro possibilita a criação de um ethos mais harmônico, em que impera a responsabilidade mútua. Quem não se abre ou não permite a fusão de horizontes não favorece a instituição de um ambiente no qual é possível sentir-se em casa e parceiro do outro.

A solidariedade, enquanto um jogo com vistas à instituição do bem comum, enquanto uma prática de fusão de horizontes linguísticos, culturais, históricos, pressupõe a contenção de interesses particulares e, por outro lado, fomenta a defesa dos interesses públicos. A título de exemplo, a natureza precisa ser tratada como mãe de todos, o que nos proíbe de instrumentalizála e nos estimula a cuidar e tratá-la como parceira da humanidade. Ou seja, a solidariedade, enquanto exercício de fusão de horizontes, retrata, corporifica e evidencia uma ética relacional, na esteira das hermenêuticas de Ricoeur e de Gadamer (SAUTEREAU, 2013, p. 294).

\section{Conclusões}

A importância e as implicações do fomento dos jogos de solidariedades vigentes, isto é, do exercício - e por isso instituir uma virtude - da fusão de horizontes entre as pessoas são de ordem ética e política. Do ponto de vista pessoal, considerando a solidariedade uma virtude hermenêutica, condensada na participação da vida do outro e fazer parte da sua vida, sua prática nos torna mais plenos e realizados (GADAMER apud RISSER, 1997, p. 20). Em termos sociais e políticos, o exercício da virtude da solidariedade, se torna imprescindível para salvação de nosso planeta, ou seja,

talvez possamos sobreviver como humanidade se pudermos aprender que não podemos simplesmente explorar nossos meios de poder e possibilidades efetivas, mas devemos aprender a parar e respeitar o outro como um outro, seja a natureza ou as culturas crescidas das pessoas e nações; e se pudermos aprender a experimentar o outro e os outros, como o outro de nós mesmos, de modo a participar com o outro (GADAMER apud RISSER, 1997, p. 20).

Em outros termos, nossa autorrealização e felicidades individuais bem como a instauração de uma convivência saudável, responsável e harmônica passam pelo exercício do jogo da solidariedade, enquanto uma incessante fusão de horizontes, própria de uma virtude ética. Dito 
de outra forma, diante das crescentes polarizações ideológicas, religiosas, políticas e das “especificidades e singularidades de uma estranheza intransponível no mundo",

se não apreendermos a virtude da hermenêutica, isto é, se não reconhecermos que se trata, em primeiro lugar, de compreender o outro, a fim de ver se, quem sabe, não será possível, afinal, algo assim como solidariedade da humanidade enquanto um todo, também, no que diz respeito a um viver junto e a um sobreviver com o outro, então se isso não acontecer - não poderemos realizar as tarefas essenciais da humanidade, nem no que tem de menor nem no que tem de maior (GADAMER, 2000, p. 25).

Jogar o jogo da solidariedade, exercitar a fusão de horizontes, implica a corporificação de uma virtude ética ao cultivar acordos consigo mesmo e com os outros. Em termos pessoais, essa prática, essa virtude nos possibilita viver felizmente e realizadamente; e em termos sociais, enquanto seres linguísticos e políticos, nos realizamos também pelo cuidado, atenção e trabalho de parceria com os outros e com a natureza. A virtude da solidariedade perpassa, assim, as demais virtudes, na medida em que pressupõe a compreensão e o cultivo de acordos consigo mesmo, com os outros, com a natureza, a fim de instaurar um ethos mais harmônico sob a égide da parceria e da responsabilidade.

Isso nos permite concluir que praticar essa virtude se tornou um imperativo em contraposição a uma "ética do niilismo infundado" (LAWN, 2007, p. 145). A recusa de jogar esse jogo constitui uma omissão política (GADAMER, 2001, p. 104) que não nos possibilitará sentirmos em casa no mundo.

A hermenêutica, enquanto um jogo de fusão de horizontes, corporificado pelo jogo da solidariedade, evidencia uma proposta ética que não se estriba em regras ou imperativos categóricos abstratos. Distintos desses, "a solidariedade é o pressuposto básico, sobre o qual a gente pode desenvolver, ainda que só lentamente, convicções comuns” (GADAMER, 2000, p. 25). O cultivo das convicções de defesa dos direitos humanos, animais e da natureza corporifica a virtude da solidariedade que contribui para nossa autorrealização, para nossa convivência harmoniosa, para salvação do nosso planeta. 


\section{Notas}

${ }^{1}$ Professor do Curso de Filosofia e do Programa de Pós-Graduação em Filosofia da Universidade do Vale do Rio do Sinos (UNISINOS), São Leopoldo, R. S., Brasil. E-mail: rohden@unisinos.br.

Este artigo contou com apoio da FAPERGS - Edital Pesquisador Gaúcho e do CNPQ - Edital Universal 2018. Registro agradecimento especial ao prof. Dr. Leonardo Kussler pela revisão do artigo.

${ }^{2}$ Hans-Georg Gadamer, A Razão na época da ciência, trad. Angela Dias (Rio de Janeiro: Tempo Brasileiro, 1983); Hans-Georg Gadamer, Herança e futuro da Europa, trad. António Hall (Lisboa: Edições 70, 1989); Hans-Georg Gadamer, O problema da consciência histórica, ed. Pierre Fruchon, trad. Paulo Cesar Duque Estrada (Rio de Janeiro: Fundação Getúlio Vargas, 1998); Hans-Georg Gadamer, "Teoria, Técnica e Prática", in O caráter oculto da saúde, Hans-Georg Gadamer, trad. Antônio Luz Costa (Petrópolis: Vozes, 2006), pp. 9-39; Hans-Georg Gadamer, "Isolamento como sintoma de auto alienação", in Elogio da Teoria, Hans-Georg Gadamer, trad. João Tiago Proença (Lisboa: Edições 70, 2001), pp. 97-108; Hans-Georg Gadamer, "Amitié et Solidarité”, in Esquisses Hermeneutiques: Essais et conférences, Hans-Georg Gadamer, trad. Jean Grondin (Paris: Vrin, 2004), pp. 79-89; Hans-Georg Gadamer, "Cidadão de dois mundos", in Hermenêutica em Retrospectiva, Hans-Georg Gadamer, trad. Marco Antonio Casanova (Petrópolis: Vozes, 2012), pp. 242-253; Hans-Georg Gadamer, "A ideia da filosofia pratica", in Hermenêtica em Retrospectiva, Hans-Georg Gadamer, trad. Marco Antonio Casanova (Petrópolis: Vozes, 2012), pp. 254-263. 


\section{Referências}

GADAMER, Hans-Georg. A Razão na época da ciência. Trad. Angela Dias. Rio de Janeiro: Tempo Brasileiro, 1983.

. Herança e futuro da Europa. Trad. António Hall. Lisboa: Edições 70, 1989.

. Griechische Philosophie, III: Plato im Dialog. Tübingen: Mohr, 1991.

. "La incapacidad para el diálogo." In Verdad y Metodo II, Hans-Georg Gadamer, trad.

Manuel Olasagasti, 203-210 (Salamanca: Ediciones Sígueme, 1992).

. Verdade e Método I. Trad. Flávio Paulo Meurer. Petrópolis: Ed. Vozes, 1997.

. O problema da consciência histórica. Ed. Pierre Fruchon, trad. Paulo Cesar Duque Estrada. Rio de Janeiro: Fundação Getúlio Vargas, 1998.

. "Da palavra ao conceito." In Hermenêutica Filosófica: nas trilhas de Hans-Georg Gadamer, ed. Custódio Luís Silva de Almeida, Hans-Georg Flickinger, Luiz Rohden, trad. Hans-Georg Flickinger, 13-26. Porto Alegre: Edipucrs, 2000.

. "Isolamento como sintoma de auto alienação." In: Elogio da Teoria, Hans-Georg Gadamer. Trad. João Tiago Proença, 97-108. Lisboa: Edições 70, 2001.

. “Amistad y solidarid.” In Acotaciones hermenéuticas, Hans-Georg Gadamer. Trad. Ana Agud, Rafael de Agapito, 77-87. Madrid: Editorial Trotta, 2002.

. Verdade e Método II. Trad. Flávio Paulo Meurer. Petrópolis: Ed. Vozes, 2002.

. "Auto-apresentação de Hans-Georg Gadamer (concluído em 1975).” In Verdade e Método II, Hans-Georg Gadamer. Trad. Flávio Paulo Meurer, 545-580. Petrópolis: Vozes, 2002.

. “Teoria, Técnica e Prática.” In O caráter oculto da saúde, Hans-Georg Gadamer. Trad. Antônio Luz Costa, 9-39. Petrópolis: Vozes, 2006.

. "Europa e o Oikoumene." In Hermenêtica em Retrospectiva. Trad. Marco Antonio Casanova, 69-82. Petrópolis: Vozes, 2007.

. "Cidadão de dois mundos.” In Hermenêutica em Retrospectiva, Hans-Georg Gadamer, trad. Marco Antonio Casanova, 242-253. Petrópolis: Vozes, 2012.

. "A ideia da filosofia prática." In Hermenêutica em Retrospectiva, Hans-Georg Gadamer, trad. Marco Antonio Casanova, 254-263. Petrópolis: Vozes, 2012.

LAWN, Chris and Kean, Niall. "Solidarity." In The Gadamer Dictionary, ed. Chris Lawn and Niall Keane, 132-135. New York: British Library, 2011. 
LAWN, Chris. Compreender Gadamer. Trad. Hélio Magri Filho. Petrópolis: Editora Vozes, 2007.

LOPES, Maria dos Santos Silva. A solidariedade como praxis hermenêtica em Gadamer. Teresina: UFPI, 2015.

ROHDEN, Luiz. Hermenêutica filosófica. São Leopoldo: Editora Unisinos, 2002.

. "Ethical Assumptions and Implications of Hermeneutical Practice as Practical Wisdom”. Études Ricoeuriennes / Ricoeur Studies, v.10, p. 5-20, 2019.

SAUTEREAU, Cyndie. Éthique et herméneutique. Une réponse des herméneutiques de Paul Ricoeur et de Hans-Georg Gadamer à l'énigme d'autrui. Québec: Université Laval, Québec, 2013.

RISSER, James. Hermeneutics and the voice of the Other: re-reading Gadamer's Philosophical Hermeneutics. New York: State University of New York Press, 1997. 